\title{
Testing angular velocity as a new metric for metabolic demands of slow-moving marine fauna: a case study with Giant spider conchs Lambis truncata
}

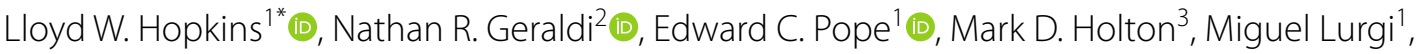 \\ Carlos M. Duarte ${ }^{2}$ and Rory P. Wilson ${ }^{1}$
}

\begin{abstract}
Background: Quantifying metabolic rate in free-living animals is invaluable in understanding the costs of behaviour and movement for individuals and communities. Dynamic body acceleration (DBA) metrics, such as vectoral DBA (VeDBA), are commonly used as proxies for the energy expenditure of movement but are of limited applicability for slow-moving species. It has recently been suggested that metrics based on angular velocity might be better suited to characterise their energetics. We investigated whether a novel metric - the'Rate of change of Rotational Movement (RocRM)', calculated from the vectoral sum of change in the pitch, roll and yaw/heading axes over a given length of time, is a suitable proxy for energy expenditure.

Results: We found that RocRM can be used as an alternative energy expenditure proxy in a slow-moving benthic invertebrate. Eleven Giant spider conchs Lambis truncata (collected in the Red Sea) were instrumented with multiple channel (Daily Diary) tags and kept in sealed chambers for $5 \mathrm{~h}$ while their oxygen consumption, $\mathrm{VO}_{2}$, was measured. We found RocRM to be positively correlated with $\mathrm{VO}_{2}$, this relationship being affected by the time-step (i.e. the range of the calculated differential) of the RocRM. Time steps of 1,5, 10 and $60 \mathrm{~s}$ yielded an explained variability of between 15 and $31 \%$. The relationship between $\mathrm{VO}_{2}$ and $\mathrm{VeDBA}$ was not statistically significant, suggesting RocRM to provide more accurate estimations of metabolic rates in L. truncata.

Conclusions: RocRM proved to be a statistically significant predictor of $\mathrm{VO}_{2}$ where VeDBA did not, validating the approach of using angular-based metrics over dynamic movement-based ones for slower moving animals. Further work is required to validate the use of RocRM for other species, particularly in animals with minimally dynamic movement, to better understand energetic costs of whole ecosystems. Unexplained variability in the models might be a consequence of the methodology used, but also likely a result of conch activity that does not manifest in movement of the shell. Additionally, density plots of mean RocRM at each time-step suggest differences in movement scales, which may collectively be useful as a species fingerprint of movement going forward.
\end{abstract}

Keywords: Angular velocity, Dynamic body acceleration (DBA), Energy expenditure, Movement costs, RocRM, Rotational movement

\footnotetext{
*Correspondence: Iloyd.william.hopkins@gmail.com

${ }^{1}$ Department of Biosciences, Singleton Campus, Swansea University,

Wallace Building, Swansea SA2 8PP, UK

Full list of author information is available at the end of the article
}

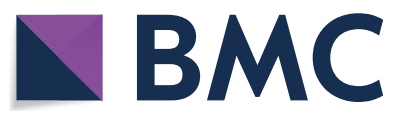

(c) The Author(s) 2021. Open Access This article is licensed under a Creative Commons Attribution 4.0 International License, which permits use, sharing, adaptation, distribution and reproduction in any medium or format, as long as you give appropriate credit to the original author(s) and the source, provide a link to the Creative Commons licence, and indicate if changes were made. The images or other third party material in this article are included in the article's Creative Commons licence, unless indicated otherwise in a credit line to the material. If material is not included in the article's Creative Commons licence and your intended use is not permitted by statutory regulation or exceeds the permitted use, you will need to obtain permission directly from the copyright holder. To view a copy of this licence, visit http://creativecommons.org/licenses/by/4.0/. The Creative Commons Public Domain Dedication waiver (http://creativeco mmons.org/publicdomain/zero/1.0/) applies to the data made available in this article, unless otherwise stated in a credit line to the data. 


\section{Background}

Animal movements, behaviours and life processes account for much of an organism's energy demands, with the process-linked metabolism of an individual determining fitness, which in turn can effect ecosystem structure and functioning [1-5]. Accurate determination of energy expenditure in animal species is therefore pivotal to understanding the value and costs of behaviours and how these relate to the ecology of species within ecosystems [6-8].

However, directly measuring the rate at which an animal expends energy in the field, where it is unrestrained and allowed to exhibit a full suite of behaviours, is challenging [9, 10]. Doubly labelled water (DLW)-measuring the rate of $\mathrm{CO}_{2}$ production, $\mathrm{VCO}_{2}$ [10-12]-is the only direct measure, while other methods, such as recording heart rate, use proxies for energy expended $[10,13,14]$. All such methods have limitations. For example, heart rate monitors are generally intrusive, often requiring implantation, and are less suitable for smaller animals [15]. The doubly labelled water method, on the other hand, is logistically difficult to conduct and has limited temporal resolution [16]. A fairly recent approach has used tri-axial accelerometers in externally attached tags to provide a less invasive and high-resolution alternative deriving 'dynamic body acceleration' (DBA) as a proxy for movement-based energy expenditure $[17,18]$. DBA is calculated from the dynamic acceleration (i.e. the acceleration signal that remains following the subtraction of static acceleration, or the gravitational component [19]) summed over all three dimension axes (x, y, z; surge, heave, sway) [20, 21].

DBA has been repeatedly shown to correlate strongly with the rate of oxygen consumption $\left(\dot{M O}_{2}\right.$ and $\left.\mathrm{VO}_{2}\right)$ in a diverse range of taxa including, inter alia, birds [20], cephalopods [22], bivalves [23], fish [24, 25] and mammals [26]. These laboratory studies have produced statistical relationships between DBA and $V \mathrm{O}_{2}$ that can be used to calculate energy expenditure from DBA extracted from accelerometer tags used on wild animals.

Despite the strength of this relationship and its applicability across many taxa, DBA is less likely to be a useful proxy for energy expended for species that move slowly because of their inherently weak dynamic acceleration signals. This limitation is indeed significant, because many marine benthic invertebrates, such as gastropods and crustaceans move slowly [27-29]. Indeed, where dynamism occurs, activity and energy expenditure within these periods may be measured by DBA metrics [28], but these may be a small percentage of the overall time budget for these animals. Lyons et al. [30], for example, showed that DBA correlated with oxygen consumption in the American lobster (Homarus americanus) during the more active periods of movement, but had limited capacity to resolve metabolic rates in periods when movement was slower.

Recently, a comprehensive review of DBA highlighted the need for alternative tag-derived metrics to address the problem posed by slow-moving species [27]. In particular, the authors suggested that rates of change of rotational axes (pitch, roll and yaw) might offer better insights into the degree of movement-and by proxy energy expenditure [17] - for such species compared to DBA ( $c f$. [31]). In other words, the movement of, for example, a benthic invertebrate, where dynamic motion is consistently negligible and often only one locomotion type is used, may be manifest most notably in the speed at which it changes its whole-body orientation. Movement along these rotational axes (assuming no drift or external factors are acting upon the animal), regardless of the speed at which this happens, still requires the exertion of force and, therefore, the expenditure of energy. Indeed, Wilson et al. [27] presented preliminary data showing clearer changes in body angular velocity during movement bouts compared to DBA in the Giant spider conch Lambis truncata. Variability in the body roll angle has since been shown to describe slow-moving (walking) activity patterns of the European spiny lobster (Palinurus elephas) much better than DBA metrics, due to very smooth acceleration signals [29].

We investigate the validity of a new metric, derived from the rates of change in rotational movement (which we term the 'Rate of Change of Rotational Movement', or 'RocRM'), as an alternative to DBA for estimating energy expenditure in a slow-moving benthic invertebrate, the Giant spider conch, L. truncata. Lambis truncata is a gastropod of the Strombidae family, a family that is commercially important and heavily overexploited in many countries [32-34]. Like many other conch species, it moves mostly via 'jumps' and rotational (about the yaw axis) 'drifts' [28, 35, 36]. In other species of conch, jumps have been shown to accompany increased oxygen consumption [37]. These jumps do produce a notable acceleration signal and the metric of mean DBA is able to differentiate between leaps and drifts in a movement recognition model [28]. Whether DBA is an accurate proxy for oxygen consumption in conchs, however, is unknown. For example, ODBA during a drift is typically much lower than during a leap [28], but might actually demand a considerable energetic commitment in practice [31,38]. With enough drift movements, therefore, it is possible that a large proportion of energetic expenditure would simply be missed by DBA metrics. An alternative metric that can capture the energetic expenditure involved in either mode of movement would therefore be preferable. The major focus of this paper is accurately capturing 
Table 1 Conch shell measurements

\begin{tabular}{|c|c|c|c|}
\hline Conch & $\begin{array}{l}\text { Max. shell width } \\
\text { (cm) }\end{array}$ & $\begin{array}{l}\text { Max. shell length } \\
\text { (cm) }\end{array}$ & $\begin{array}{l}\text { Calculated } \\
\text { approximate } \\
\text { volume }\left(\mathrm{cm}^{3}\right)\end{array}$ \\
\hline 1 & 11 & 17 & 1047 \\
\hline 2 & 12 & 19 & 1277 \\
\hline 3 & 11 & 14 & 739 \\
\hline 4 & 10 & 14 & 1008 \\
\hline 5 & 11 & 15 & 1188 \\
\hline 6 & 9 & 14 & 806 \\
\hline 7 & 12 & 16 & 1382 \\
\hline 8 & 11 & 16 & 1126 \\
\hline 9 & 11 & 16 & 1126 \\
\hline 10 & 12 & 17 & 1469 \\
\hline 11 & 13 & 17 & 1591 \\
\hline Mean & $11.2( \pm 1.1 \mathrm{sd})$ & $15.9( \pm 1.6 \mathrm{sd})$ & $1159.9( \pm 261.9)$ \\
\hline
\end{tabular}

Measurements, to the nearest whole $\mathrm{cm}$, of maximum length and width of conchs used in this study and their approximate volumes

these drift movements. We used laboratory-based static respirometry to test the hypothesis that RocRM correlates with the rate of oxygen consumption in a slow-moving animal. We further examined how RocRM compared to DBA as a predictor of $\mathrm{VO}_{2}$ in this species. We hypothesised that RocRM would correlate more strongly with $\mathrm{VO}_{2}$ than DBA.

\section{Methods}

\section{Animal collection and holding facilities}

Eleven Giant spider conchs, Lambis truncata sebae (Kiener 1843), were collected by snorkellers from areas of rubble and coarse sand on a shallow $(<1 \mathrm{~m})$ reef bed near the KAUST campus, Saudi Arabia, in the Red Sea during February 2019. Similarly sized conchs were selected (maximum width and length of shells, measured to the nearest $\mathrm{cm}$, are shown in Table 1). A GPS fix (using a handheld GPS 73 unit; Garmin, Schaffhausen, Switzerland) was taken of what was deemed to be the most representative of the area where the specimens were collected from $\left(22^{\circ} 17^{\prime} 22.7^{\prime \prime} \mathrm{N}, 39^{\circ} 03^{\prime} 25.5^{\prime \prime} \mathrm{E}\right)$, with all individuals being found within a $50 \mathrm{~m}$ radius.

Specimens were housed in two separate holding tanks (dimensions $118 \times 56 \times 46 \mathrm{~cm} \mathrm{~L} \times \mathrm{W} \times \mathrm{H}$ ) supplied with a continuous flow of seawater, pumped directly from the neighbouring Red Sea and then micro-filtered. The water level in the holding tanks was $40 \mathrm{~cm}$ (ca. 264 L). Tanks of the same size were used during experiments.

Animals were kept in their holding tanks for 3 days prior to experiments and fed throughout the trial on the algal film that was allowed to coat the tank walls. The shells of the conchs were cleaned with a rigid brush to remove as much biological growth as possible and

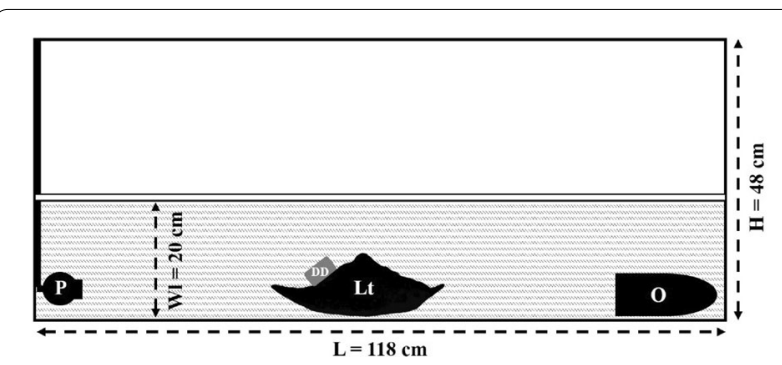

Fig. 1 Schematic diagram of the static respirometry setup used in this study. $\mathrm{H}=$ the total height of the tank; $\mathrm{L}=$ the total length of the tank; $P$ = the water circulation pump, powered externally; $\mathrm{WI}=$ the water level in the tank (shaded area); Lt = L. truncata test animal; $\mathrm{DD}=$ the Daily Diary tag, positioned on the 'front' of the animal; $\mathrm{O}=$ the miniDOT $\mathrm{O}_{2}$ logger, weighed down to the bottom of the tank. The white rectangle at the top of the water line depicts the plastic sheeting cover used to seal the tank

further cleaning was carried out when deemed necessary throughout the experimental period to minimise the effect of non-conch oxygen consumption during respirometry. However, conchs were not cleaned within $24 \mathrm{~h}$ of being experimentally tested, to reduce the potential stress of handling.

\section{Respirometry experiments Overview}

The tanks used in the respirometry experiments (see above) were chosen to encourage 'normal' conch movement during the experiments; the tanks were large enough to allow short periods of traversal. Before each trial, the water flow into the tank was stopped and the tanks drained to a water level of $20 \mathrm{~cm}$. This water height was more than sufficient to allow 'jumping' movement without the conch touching the plastic top covering. Flow was restored between experiments and left long enough to completely replace the water. Air was bubbled through the water prior to the start of the experiment to fully oxygenate the water. A water pump was used to circulate the water within the tank to reduce both microbial build-up on the sensor foil and oxygen stratification inside the respirometer (tank), providing more consistent estimates of both background respiration and the $\mathrm{VO}_{2}$ of the study animal [39]. MiniDOT $\mathrm{O}_{2}$ sensor loggers (PME, California, USA) were anchored to the bottom of the tank at the end opposite to the pump (Fig. 1), with the sensing face pointing towards the tank centre.

Respirometry trials were conducted using closed chamber/static respirometer techniques [40]. For the control/ blank runs, initial trials (i.e. when calibrating equipment) and in the experiments themselves, aquaria were sealed with plastic sheeting (similar to those described in [25] and [41]) so as to be gas tight. Four layers of 1-mm-thick 
sheeting were bonded together with duct tape (taking care that the complete material was watertight) to ensure that the final cover had enough weight to rest against the water and push out trapped air. The sheet was sealed to the tank walls as close as possible to the water level using duct tape and the seal inspected for any obvious gaps or unwanted gas exchange. Air bubbles between the water and plastic were pushed out by smoothing the plastic towards the edges until none remained. Care was taken to seal around the water pump cable in such a way as to also be airtight. The salinity of the water was measured following each experiment and control using a Pro Plus Quatro salinity probe (YSI, Ohio, USA).

\section{Data loggers}

Water-dissolved oxygen concentration $(\mathrm{mg} / \mathrm{L} \mathrm{DO})$ and water temperature were measured with the miniDOT loggers, with temperature corrections applied automatically by the sensor. Salinity corrections of DO required manual input of salinity using provided 'miniDOT concatenate' software. MiniDOT loggers took one reading of each variable every $30 \mathrm{~s}$-the minimum time that $\mathrm{O}_{2}$ was predicted to take to diffuse through the sensing foil (PME, pers. comm.) and therefore the shortest interval that could be confidently used. The sensing foil was cleaned between each trial.

Conch movement was recorded using an 'elongated' model Daily Diary tag (Wildbyte Technologies Ltd., UK), recording tri-axial acceleration (surge, heave and sway) and tri-axial magnetometry at $20 \mathrm{~Hz}$. Each Daily Diary was powered by a $750 \mathrm{mAh}, 3.6 \mathrm{~V}$ single-use battery (EVE Energy Co., China). The complete package was enclosed within a vacuform polystyrene plastic housing and sealed using Poly Cement (Humbrol, Hornby Hobbies, UK). The overall maximum package dimensions were $38 \times 20 \times$ $13 \mathrm{~mm} \mathrm{~L} \times \mathrm{W} \times \mathrm{H}$ with a weight in air of $6 \mathrm{~g}$. Velcro (Velcro BVBA, UK) was glued to the Daily Diary package. All conchs had a $1.5 \times 1.5 \mathrm{~cm}$ patch of complementary Velcro fixed to their shell using super glue (Loctite Power Flex, Loctite, Germany), at an approximately $25^{\circ}-30^{\circ}$ angle on the anterior shell spine (as it was an area conserved between individuals, close to the centre of mass, and relatively flat for ease of attachment). The Daily Diary package was attached to the animal during transfer of the conch from holding to experiment tanks and removed when conchs were returned to holding tanks.

\section{Respirometry experiments}

The Daily Diary-equipped conchs were allowed to settle within their testing tanks for at least $30 \mathrm{~min}$ prior to experimentation, with the miniDOT loggers placed in the tank at the same time. Tanks were sealed for $5 \mathrm{~h}$ and the DO and conch movement (via the Daily Diaries) recorded throughout this time. To increase the number of tests, conchs were tested four times across two general time periods (twice each): (1) 'afternoon' (average start and end times $=11: 04$ and 15:59, respectively-Saudi Arabia local time $=$ GMT +3 ) and 'evening' (average start and end times $=17: 36$ and 22:30, respectively). These times were used as preliminary work had shown L. truncata collected from this area appear to slowly increase their movement through the late afternoon and evening (unpublished data), therefore giving the best chance of capturing different 'levels' of movement frequency. Conchs were not reused in an experiment for at least $24 \mathrm{~h}$.

All conchs were released following respirometry experiments and returned as close to their collection location as possible. The Velcro patch and glue were easily removed, leaving only superficial markings.

\section{Calibrations and controls}

A control/blank tank, without conchs, was included for both time periods mentioned ( 3 in the afternoon and 4 in the evening), lasting at least $5 \mathrm{~h}$ each. Blank runs were used to assess microbial ('background') $\mathrm{VO}_{2}$. The average conch respirometry experiment start and end times informed the times used in calculations of corrections. Two mean control slopes, for afternoon and evening periods, were calculated from linear regression of each control run. Each conch $\mathrm{VO}_{2}$ calculation was subsequently corrected for microbial $\mathrm{VO}_{2}$ through subtraction of control rates (see [39]). The lowest recorded DO concentration in any experiment was $5.75 \mathrm{mg} / \mathrm{L}\left(87.54 \% \mathrm{O}_{2}\right.$ saturation).

\section{Data analysis \\ VO2}

The strength of the relationship of $\mathrm{VO}_{2}$ as a function of time (as a linear model) was evaluated immediately after each experiment run, to check that the system was sealed sufficiently and that there was a generally consistent negative correlation. Origin 2019 (Origin Lab Corp., Massachusetts, USA) was used to compute $R^{2}$ values for this. Experiment runs were repeated if plots suggested erratic DO readings (potentially due to poor chamber sealing) or a low $R^{2}$ value comparing oxygen concentration and time (in the final analysis, all slopes had an $R^{2}$ of $>0.87$ ). As a result of the corrections discussed in 2.2.3, three experiments were discounted due to background-corrected slopes turning positive (suggesting breaches in the tank sealing), all of which were in the afternoon period, leaving 41 slopes across 11 conchs (3 conchs with 3 slopes, all others with 4 slopes) to 
be used in statistical analysis. Of these, five experiments did not record for the complete 5 hours $(240,267,271,286$, $295 \mathrm{~min}$, respectively), but were included in all analyses.

$\mathrm{VO}_{2}$ for a single organism in a static system was calculated as in [40]:

$$
\dot{V} \mathrm{O}_{2}=\Delta\left[\mathrm{O}_{2}\right] . V_{\text {ind }},
$$

where $\Delta\left[\mathrm{O}_{2}\right]$ is the regression slope of $\mathrm{O}_{2}$ in milligrammes per litre per hour, $V_{\text {ind }}$ is the water volume in litres specific to the tested individual and $\mathrm{VO}_{2}$ is the rate of $\mathrm{O}_{2}$ consumption for that individual in the same time units as the slope $\left(\mathrm{mg}\right.$ ind $\left.\mathrm{d}^{-1} \mathrm{~h}^{-1}\right) . V_{\text {ind }}$ was calculated as the effective tank volume $\left(1,32,160 \mathrm{~cm}^{3}\right)$ minus the volume of the miniDOT logger $\left(314.16 \mathrm{~cm}^{3}\right)$, the water pump $\left(179.59 \mathrm{~cm}^{3}\right)$ and the conch (calculated for each individual; see Table 1).

\section{Movement}

Daily Diary data were preliminarily analysed and data extracted using DDMT (Daily Diary Multiple Trace) software (Wildbyte Technologies Ltd, UK). Acceleration (1 g = $9.81 \mathrm{~m} / \mathrm{s}^{2}$ ) was separated into dynamic and static (postural) components using a smoothing window of $3 \mathrm{~s}$ [the window length informed by Shepard et al. [19] and previously collected data on the movement durations of this species (unpublished data)].

Daily Diary data were used to calculate two movement metrics for each conch experiment run: RocRM and VeDBA.

The RocRM metric was calculated from the vectoral sum of the change (differential) in pitch, roll and heading over a specified time-step given by:

$$
\operatorname{RocRM}=\sqrt{\operatorname{Roc}_{p}^{2}+\operatorname{Roc}_{r}^{2}+\operatorname{Roc}_{h}^{2}},
$$

where $\operatorname{Roc}_{p}$, $\operatorname{Roc}_{r}$ and $\operatorname{Roc}_{h}$ refer to the rate of change in the angles of pitch, roll and heading, over the given timestep, respectively. The rate of change over a time-step is calculated within a moving window, therefore RocRM is presented as a continuous variable. Pitch and roll angle were derived from postural acceleration data [42] while heading is derived from the body orientation data in tandem with the geomagnetic field strength measured in three axes [43]. Specifically, pitch and roll were calculated as:

$$
\begin{aligned}
& \operatorname{Pitch}(p)=\operatorname{atan} 2\left(S_{x}, \sqrt{S_{y}^{2}+S_{z}^{2}}\right) \cdot \frac{180}{\pi}, \\
& \operatorname{Roll}(r)=\operatorname{atan} 2\left(S_{y}, \sqrt{S_{x}^{2}+S_{z}^{2}}\right) \cdot \frac{180}{\pi},
\end{aligned}
$$

where $S_{x} S_{y}$ and $S_{z}$ are the static acceleration as recorded on the heave, surge and sway axes, respectively. Heading was derived as:

$$
\text { Heading }(h)=\bmod \left\{\left[\operatorname{atan} 2\left(-m_{y}, m_{x}\right) \cdot \frac{180}{\pi}\right], 360\right\},
$$

where $m_{x}$ and $m_{y}$ refer to the $x$ and $y$ magnetometer channels following normalisation (to bring the data onto a sphere) and rotational correction (using pitch and roll to account for device tilt) and mod refers to the modulo operator [44].

There was some magnetic noise within the tanks due to the pump, so heading was smoothed over $5 \mathrm{~s}$. For consistency, pitch and roll were also smoothed over $5 \mathrm{~s}$. RocRM was subsequently calculated for four different time-steps (i.e. the vectoral sum of the change in these smoothed channels); over $1 \mathrm{~s}\left(\operatorname{RocRM}_{1}\right), 5 \mathrm{~s}\left(\operatorname{RocRM}_{5}\right)$, $10 \mathrm{~s}\left(\operatorname{RocRM}_{10}\right)$ and $60 \mathrm{~s}\left(\operatorname{RocRM}_{60}\right)$.

The dynamic component of acceleration, used in calculating VeDBA, was calculated as:

Dynamic acceleration

$=$ total acceleration - static acceleration.

VeDBA (measured in $g$ ) was calculated using the formulation proposed by Qasem et al. [21]:

$$
\mathrm{VeDBA}=\sqrt{A_{x}^{2}+A_{y}^{2}+A_{z}^{2}},
$$

where $A_{x}, A_{y}$ and $A_{z}$ are the dynamic accelerations from each of the tri-axial channels at any given time. To be consistent with pitch, roll and heading, VeDBA was also subsequently smoothed over $5 \mathrm{~s}$ prior to statistical analysis.

Overall means for VeDBA and each RocRM measure were calculated for each experiment run and matched to their corresponding $\mathrm{VO}_{2}$ measurement.

Kernel density distributions of the four different RocRM time-steps were calculated to provide an overview of the differences between timescales of conch movement.

\section{Statistical analyses}

Statistical analyses were conducted in $\mathrm{R}$ [45] version 3.6.0. Five linear mixed models (LMMs) were constructed to investigate the relationship between $\mathrm{VO}_{2}$ and each one of the movement metrics independently, using the lme4 package [46] version 1.1.21. Thus, in each model, $\mathrm{VO}_{2}$ was the response variable and $\log (\mathrm{VeDBA}), \log ($ mean

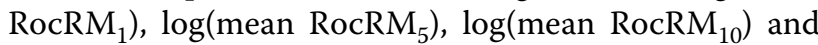
$\log \left(\right.$ mean $\left.\operatorname{RocRM}_{60}\right)$ were included as predictor variables in their respective models (subscript refers to the differential time-step period in seconds). To account for 
potential dependency of observations obtained from the same individual, 'conch individual' was included as a random-effect term in all models. All models included random intercepts only (i.e. only the by-individual intercept, and not the slope, were allowed to vary), as attempts to fit random slopes for the conch ID term had issues with singularity. Mean experiment temperature was initially included as a fixed effect in each model, but was removed from all of them through stepwise elimination of terms through ANOVA comparisons of models (see Additional file 1), as well as judged on Akaike Information Criterion (AIC) values, starting with the full model [47].

Likelihood ratio tests ( $\mathrm{R}$ function ANOVA, with Maximum Likelihood) were used to determine the validity, effect size and significance of full versus null models. Graphical procedures $(\mathrm{Q}-\mathrm{Q}$ plot, histograms, and residual vs fitted value plots) were used to visually assess the fit of the model and adherence to assumptions of normality and homoscedasticity of residuals Zuur et al. [48]. RocRM was log-transformed to better meet these assumptions. VeDBA was also log-transformed, to make comparisons between models fairer and clearer, although in practice the VeDBA models were near identical. Pseudo- $R^{2}$ values in the form of marginal $\left(R_{m}^{2}\right)$ and conditional $\left(R_{c}^{2}\right)$ values-where the conditional value considers the full model and the marginal value considers the fixed model effects alone relative to the conditional value-were calculated according to Nakagawa and Schielzeth [49]. 95\% confidence intervals were computed via a bootstrapping method using the 'confint' (type = 'percentile', $n=500$ ) function within lme4 [46]. The 95\% prediction interval was also calculated (using the calculator provided in [50]) for each reported $p$ value, allowing comment on the $p$ value uncertainty and replicability [51].

Where $p \leq 0.37, p$ values were additionally converted into Bayes factor upper bounds $(\bar{B})$ values, giving the odds of the alternative hypothesis being true over the null hypothesis $[51,52] . \bar{B}$ values were calculated following the equation in [51]:

$$
\bar{B} \leq \frac{-1}{e \times p \times \ln (p)},
$$

where ' $p$ ' is the model $p$ value.

AIC evidence ratios, comparing the relative likelihood of one model over another [51], were calculated according to:

$$
\mathrm{ER}=\frac{1}{\mathrm{e}^{-0.5 \times \Delta \mathrm{AIC}}},
$$

where $\triangle \mathrm{AIC}$ is the difference in AIC between the two models of the interest. Note that the equation denominator calculates the relative evidence for a given model.

\section{Results \\ Controls}

The mean background $\mathrm{VO}_{2}$ slopes of the 'afternoon' and 'evening' controls were -2.98 and $-4.03 \mathrm{mg} \mathrm{h}^{-1}$, respectively. Despite the use of micro-filtered water in these experiments, there remained a clear presence of background/microbial respiration, particularly in the evening period, requiring the use of these corrections.

\section{Differences in movement traces between VeDBA and RocRM}

Movement data traces of rotational movement axes, VeDBA and RocRM reveal appreciable differences in the RocRM signal with different movement types (Fig. 2). RocRM $_{10}$ movement peaks differed between movements predominantly in the pitch and roll axes, exhibiting split peaks, and those predominantly in the heading/yaw axis, exhibiting peaks that are more singular. VeDBA, in contrast, produced relatively consistent peaks.

All RocRM time-steps $(1,5,10$ or $60 \mathrm{~s})$ had a positive skew of mean values (Fig. 3), with increasing values of RocRM with increasing time-step as well as increasing interquartile range (IQR) relative to the median value $\left(\right.$ RocRM $_{1}$ : median $=0.13, \mathrm{IQR}=0.07 ; \operatorname{RocRM}_{5}$ : median $=0.37, \mathrm{IQR}=0.26 ; \operatorname{RocRM}_{10}:$ median $=0.49$, $\mathrm{IQR}=0.43, \operatorname{RocRM}_{60}:$ median $=1.43, \mathrm{IQR}=1.76$ ).

\section{RocRM as a proxy for oxygen consumption}

Mean temperature was removed from all five models due following ANOVA tests between models with and without the term (VeDBA model: $\chi^{2}(1)=0.05, p=$ 0.83; $\operatorname{RocRM}_{1}: \chi^{2}(1)=0.001, p=0.97 ; \operatorname{RocRM}_{5}: \chi^{2}$ $(1)=0.22, p=0.63 ; \operatorname{RocRM}_{10}: \chi^{2}(1)=0.01, p=0.91$; $\left.\operatorname{RocRM}_{60}: \chi^{2}(1)=0.09, p=0.77\right)$. See Additional file 1 for further details.

Log-transformed mean VeDBA was not a statistically significant predictor of $\mathrm{VO}_{2} \mathrm{mg}$ ind $^{-1} \mathrm{~h}^{-1}$ with large confidence interval bands (which include 0) and an $R_{m}^{2}$ of 0.01 (Table 2; Fig. 4). In contrast, log-transformed mean RocRM increased with $\mathrm{VO}_{2}$ (Table 2; Fig. 4) at all timesteps, with smaller (statistically significant) $p$ values for larger time-steps. $R_{m}^{2}$ values increased with increasing RocRM time-step $(0.15,0.18,0.23$ and 0.31$) .95 \%$ prediction interval bands for these $p$ values indicated increasing replicability of the model comparison outcome with increasing time-step of RocRM. 


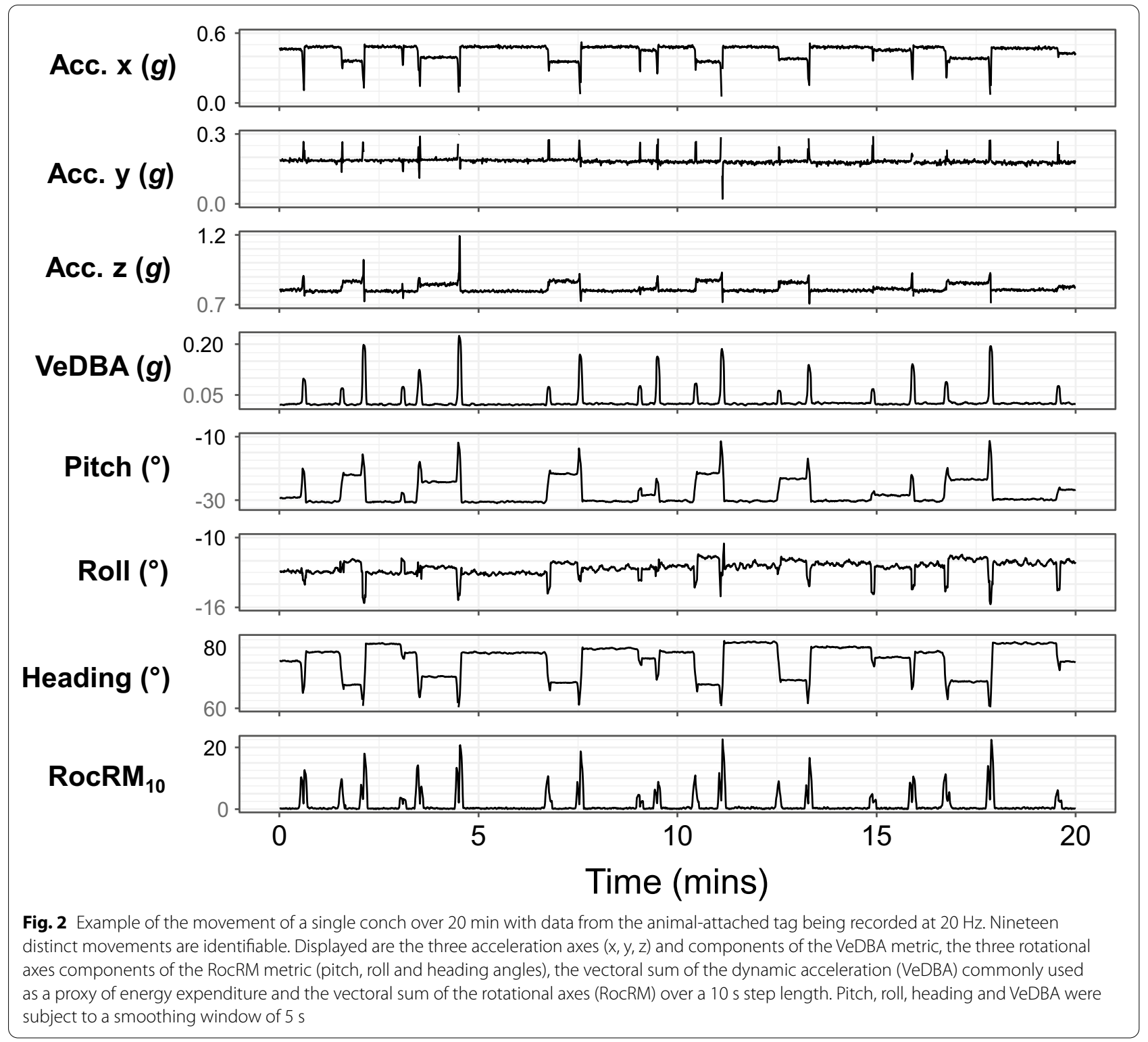

$\bar{B}$ values for RocRM models also increased with increasing time-step. For RocRM time-steps of 1, 5, 10 and $60 \mathrm{~s}$, the alternative hypothesis (that there is a difference between the full and null models) was at most $16.66,53.26,83,86$ and 685.31 times as likely as the null hypothesis (that there is no difference between the full and null models). BFUB could not be reported for the VeDBA model as the $p$ value was $>0.37$.

AIC-derived evidence ratios showed similar trends, with increasing evidence for the full model over the null model with increasing RocRM time-step. ER for RocRM time-steps of 10 and $60 \mathrm{~s}$ were particularly large. By contrast, ER for the VeDBA showed that the evidence for the full model was just 2.66 times as strong as for the null model.

\section{Discussion}

Dynamic body acceleration is the prevalent tag-derived metric by which to quantify energetic expenditure of animal movement. This methodology appears flawed in slow-moving organisms. Novel ways of assessing movement and their effects on metabolic rates are needed to better understand slow-moving species movements. Here we have shown that RocRM, a movement metric based on angular velocity about the three rotational axes (pitch, roll, yaw), is a good proxy for estimating 


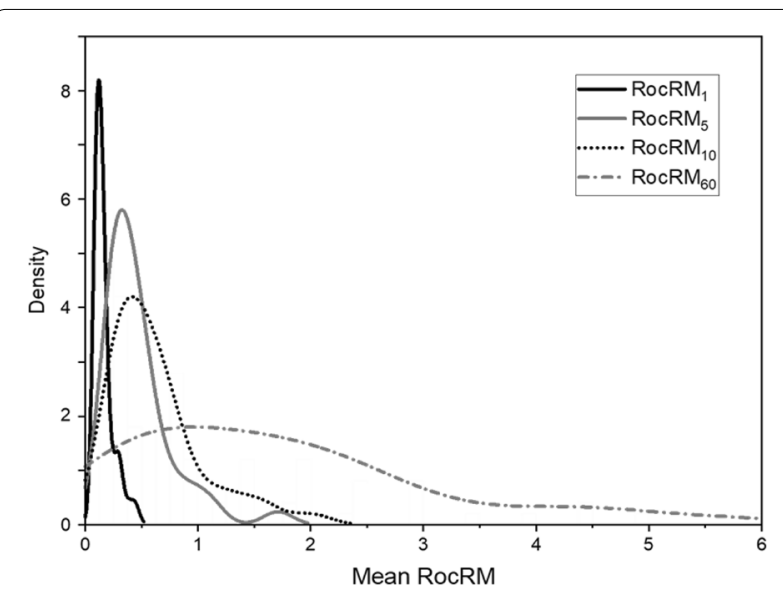

Fig. 3 Density distributions of the 5-h mean RocRM values for each time-step (where 'time-step' refers to the time interval of the differential that RocRM was calculated over- either 1, 5, 10 or $60 \mathrm{~s}$ ) that fine-scale behaviours in diving loggerhead turtles are manifest most noticeably in the angular velocity about the yaw axis [44].

Clearly, however, there is a sizeable source of variation around the predicted relationship not accounted for by RocRM, indicated by the confidence intervals and modest marginal $R^{2}$ values for shorter RocRM time-steps (particularly 1 and $5 \mathrm{~s}$ ). Firstly, the need to place Daily Diaries on the hard shell of the conch inevitably means that conch activity that does not manifest in the movement of the shell is unaccounted for. For example, conchs feed using their proboscis whilst grazing $[35,53]$, which does not result in the movement of the shell [28]. The proportion of time, and energetic expenditure, that such movements account for is unknown, but might explain the variance in $V \mathrm{~V}_{2}$ at the lowest RocRM values. We also note that we did not consider the non-movement ener-

Table 2 Linear mixed model results

\begin{tabular}{|c|c|c|c|c|c|c|c|c|c|}
\hline Model & Predictor & Est & $\mathrm{Cl}$ & $t$ & $p(\mathrm{PI})$ & $\bar{B}$ & $x^{2}(d f)$ & $\Delta \mathrm{AIC}(\mathrm{ER})$ & $R_{m}^{2} / R_{c}^{2 a}$ \\
\hline \multirow[t]{2}{*}{1} & Intercept & 4.20 & $19.24-27.64$ & 2.49 & . & & & & \\
\hline & $\log ($ mean VeDBA) & -0.37 & $-6.74-5.99$ & -0.51 & $(0.0001-1)$ & & $0.03(1)$ & $1.96(2.66)$ & $0.01 / 0.10$ \\
\hline \multirow[t]{2}{*}{2} & Intercept & 10.54 & $6.74-14.27$ & 5.82 & $* * *$ & & & & \\
\hline & $\log ($ mean RocRM 1$)$ & 2.59 & $0.73-4.28$ & 2.87 & $\left(7.11^{-6}-0.56\right)^{*}$ & 16.66 & $6.40(1)$ & $4.4(9.02)$ & $0.15 / 0.41$ \\
\hline \multirow[t]{2}{*}{3} & Intercept & 7.61 & $6.10-9.19$ & 9.27 & $* * *$ & & & & \\
\hline & $\log \left(\right.$ mean $\left.\operatorname{RocRM}_{5}\right)$ & 2.26 & $1.01-3.55$ & 3.19 & $\left(1.1^{-6}-0.34\right)^{* *}$ & 53.26 & $8.46(1)$ & $6.46(25.28)$ & $0.18 / 0.40$ \\
\hline \multirow[t]{2}{*}{4} & Intercept & 7.06 & $5.67-8.22$ & 11.00 & $* * *$ & & & & \\
\hline & $\log \left(\right.$ mean $\left.\operatorname{RocRM}_{10}\right)$ & 2.32 & $1.03-3.54$ & 3.84 & $\left(6.909^{-8}-0.14\right)^{* * *}$ & 83.86 & $11.79(1)$ & $9.79(133.62)$ & $0.23 / 0.46$ \\
\hline \multirow[t]{2}{*}{5} & Intercept & 5.25 & $4.27-6.09$ & 10.74 & $* * *$ & & & & \\
\hline & $\log \left(\right.$ mean $\left.\operatorname{RocRM}_{60}\right)$ & 1.68 & $0.95-2.37$ & 4.57 & $\left(2.04^{-9}-0.04\right)^{* * *}$ & 685.31 & $16.28(1)$ & $14.28(1261.43)$ & $0.31 / 0.51$ \\
\hline
\end{tabular}

Results of the final (following removal of terms through stepwise elimination) linear mixed models where $\mathrm{VO}_{2} \mathrm{mg} \mathrm{ind}^{-1} \mathrm{~h}^{-1}$ is predicted by either log-transformed mean VeDBA or log-transformed mean RocRM (over either $1 \mathrm{~s}, 5 \mathrm{~s}, 10 \mathrm{~s}$ or $60 \mathrm{~s}$ stepping value)

$\mathrm{PI}$ refers to the prediction interval of the $p$ value

$\triangle \mathrm{AIC}$ refers to the difference between the null and full models, as shown by ANOVA model comparison, and ER refers to the AIC evidence ratio

$\bar{B}$ refers to Bayes factor upper bound. $A \bar{B}$ was not calculated for Model 1 due to the $p$ value being $>0.37$

${ }^{\text {a }} R_{m}^{2}$ (marginal $R^{2}$ ) refers to the variance of the (final) linear mixed model explained by only the fixed-effect terms, whereas $R^{2}{ }_{c}$ (conditional $R^{2}$ ) refers to the variance explained by both fixed- and random-effect model terms [49]

$.{ }^{\prime \prime *}, \prime^{* * \prime}$ and ${ }^{\prime * * * \prime}$ refer to $p$ values of $>0.05,<0.05,<0.01$ and $<0.001$, respectively

energy expenditure in free-living spider conchs. The evidence is most convincing for time-steps of 10 and 60 s. Given the lack of a relationship between $\mathrm{VO}_{2}$ and VeDBA in this study, it appears that rotationalbased metrics may provide a critical movement-linked energy metric where dynamism-based ones do not. These results support the suggested advantage of rotational metrics from preliminary data on conch movement presented in Wilson et al. [27]. They also build upon previous studies that show how slow-moving data in the European spiny lobster, $P$. elephas, is best described in terms of pitch and roll metrics [29] and getic contributions of specific dynamic action (SDA) [54]. As conchs were allowed to graze whilst in their holding tanks on the growing algal film, the metabolic demands of digestion could well be relevant here. Indeed, other studies on gastropod species have found a postprandial peak following algal film feeding (see Table 2 of [54] and the references therein). Disentangling this effect, whether by explicitly studying the SDA of $L$. truncata in this context or by eliminating any food source in studies to validate our results, would certainly help clarify the extent of this potential variation. 

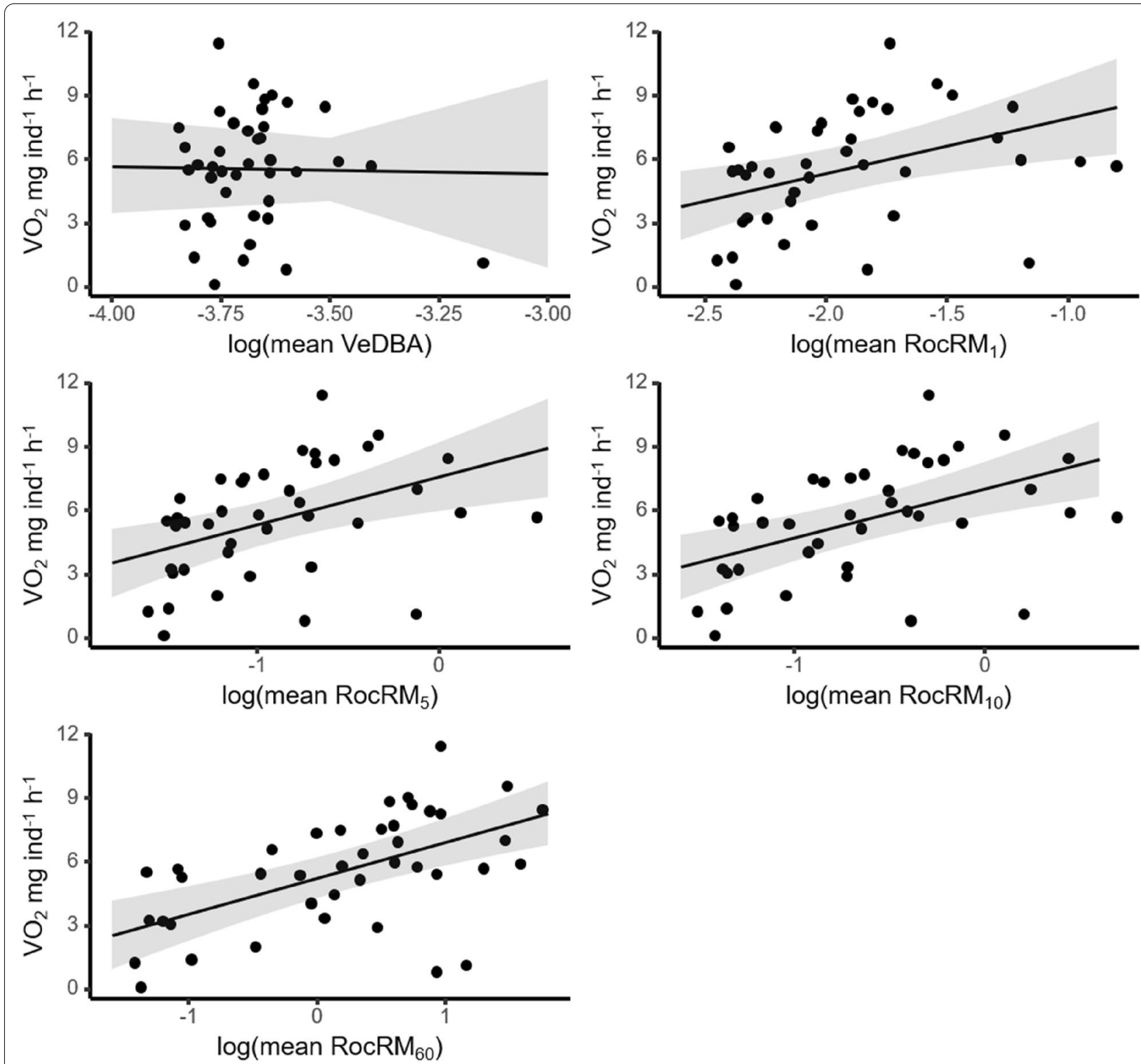

Fig. 4 Oxygen consumption in Lambis truncata is well explained by RocRM but not VeDBA. Relationships between oxygen consumption (VO, $\mathrm{mg}$ ind $\left.^{-1} \mathrm{~h}^{-1}\right)$ and either mean log-transformed VeDBA or four different time-steps of log-transformed mean RocRM (1, 5, 10 or 60 s). Trend lines show the fitted relationships calculated from linear mixed models (LMMs) with 95\% confidence intervals

We also suggest that the method used here, using an overall mean taken over approximately $5 \mathrm{~h}$, misses the shorter, more intense bouts of movement that might produce higher RocRM. However, reducing the time period over which $\mathrm{VO}_{2}$ is measured is likely to increase the error around $\mathrm{VO}_{2}$ estimates derived from the limitations in detecting very small changes in $\mathrm{O}_{2}$ in a relatively large volume of water, especially as 'high' activity periods are brief. Nonetheless, further tests using more sensitive oxygen sensors may refine our work further.
The sensor probes employed here could reliably measure $\mathrm{O}_{2}$ concentration only to a minimum resolution of once every $30 \mathrm{~s}$, due to the traversal time of $\mathrm{O}_{2}$ across the sensing foil. Other studies regularly employ probes taking measurements once per second $[55,56]$ and their use here would certainly have allow a more finely resolved $\mathrm{VO}_{2}$-RocRM relationship to be quantified.

Conversely, reduction of the water volume, which might mitigate some of this problem, will tend to constrain animal movement. Our experimental set-up 
differed from many 'traditional' respirometry studies that use fixed-volume, solid-walled, smaller (relative to the animal's body size) chambers, which would constrain animal movement. The tank volume employed here, approximately 114 times the volume of the conchs, allowed enough room for the animals to move in concentrated bouts. ${ }^{1}$ We note previous studies [25, 41] on blacktip (Carcharhinus limbatus) and lemon (Negaprion brevirostris) sharks encouraged consistent movement by having an animal to chamber volume ratio approximately two times larger than ours, although these animals are considerably more mobile than the spider conchs tested here. Any tank setup will restrict normal movement, of course. When coming up against a barrier to movement, conchs will often continue to try to move up against it until they can move again [28] - if this happened here, then it is possible that conchs would have expended large amounts of energy for what would appear, from the Daily Diary data, to be limited movement of the shell.

As the respirometry chamber had a soft plastic top in place of a solid lid, it is feasible that any conchs climbing up the tank sides could break the airtight seal by pushing the plastic covering away from the water's surface. Conchs were regularly observed throughout the actual trials, however, and were never seen to climb the experiment tank sides beyond propping themselves at an angle between the sides and tanks bottom. As well as their greater weight and size compared to many gastropods, the lack of tortuous substrate may have stopped the conchs, whose shells are bigger and more protruding than many gastropods, from being able to traverse a $90^{\circ}$ angle.

Chamber volume may not be the only factor affecting results. An important consideration when applying this relationship to free-living conchs is how the animal moves in relation to, and as a consequence of, its environment. Specifically, the substrate across which the conch travels will alter the relative contributions of changes in pitch, roll and yaw/heading. Further, the substrate may also negate or emphasise the inclusion of one or more rotational axes as part of RocRM. In simple respirometry chambers with flat bottoms as used here, pitch and roll changes are likely to make a smaller contribution towards the overall mean RocRM than if the animal was traversing rocky, uneven substrate such as the coral rubble that

\footnotetext{
1 'Bouts' were considered to be groups of movements that interspersed nonmovement periods (the non-movement periods lasting at least several minutes). Bouts lasted anywhere from $<1 \mathrm{~min}$ to $>15 \mathrm{~min}$. Unpublished data on this species in the field have shown that $28.5 \%$ and $81.2 \%$ of movements occurred after an interval of $<1 \mathrm{~min}$ and $<10 \mathrm{~min}$, respectively, with minimum and maximum between-movement times of 0.01 and $508.6 \mathrm{~min}$, respectively.
}

many conch species prefer [36]. Simulating such environments in respirometry conditions poses difficulties in, for example, the proper mixing of water and calculations of water volume when using fixed-volume chambers, as well as providing more substrate for microbes which may affect $\mathrm{O}_{2}$ measures. Nonetheless, comparison of different substrate rugosity/complexity in future studies would certainly improve the application of the RocRM- $\mathrm{VO} 2$ relationship for a given subject species. The movement bout of the individual depicted in Fig. 2 suggests that changes in yaw/heading correspond closely to that of pitch, contrasting with a more negligible change in the roll. This is unsurprising, as the way in which the conch raises itself up onto its foot during a directional change will lead to a pitch change of the animal $[28,35]$. As very few, if any, benthic animals move without any change whatsoever in at least two rotational axes, it would seem prudent to include all three axes as part of RocRM predictions of energy expenditure until further work indicates otherwise.

Apparent circadian rhythms were responsible for difference in movement levels, matching subsequently collected data on free-roaming $L$. truncata showing nocturnal preferences in movement (unpublished data; see also Additional file 1 on the difference in VeDBA and RocRM between afternoon and evening periods). This was good from a perspective of finding a range of activities (i.e. data representative of both higher and lower movement levels). Interpretation of this would have been enhanced had we known more about the natural circadian behaviour of this study species, so that we might have been able to target periods of greater movement intensity.

In the frame of slow-moving animals that exhibit little-to-no dynamic acceleration signal (sensu Gleiss et al. [17]), the actual 'jump' of L. truncata is surprisingly dynamic - at least by comparison to the steadier motion of other invertebrates, such as crustaceans or urchins. These jumps do produce spikes in VeDBA, as seen in Fig. 2. However, the instances of these jumps were seemingly insufficiently large, or did not occur often enough, to make a difference in the relationship between VeDBA and $\mathrm{VO}_{2}$ over the 5-h time scale employed here-unsurprising when surge, heave and sway axes produce a vastly lower signal during these drifts [28]. In fact, in many instances, changes of heading were not even accompanied by a discernible change in acceleration, pitch or roll. The apparently greater contribution of drifts compared to jumps might also be a result of context-exploration of a small tank rather than an open benthic environment leading to the conch having less of a straight line path on which to jump continuously. It is also reasonable to assume that these jumps are at least partly anaerobic in 
nature, leading to a degree of post-exercise oxygen consumption (EPOC) [57]. Indeed, leaping bursts in other conch species lead to anaerobic-metabolism enzyme build-up [58] and EPOC up to $12 \mathrm{~h}$ post-burst [37]. We would suggest that our 5-h should account for at least part of this effect. However, more finely resolved $\mathrm{VO}_{2}$ measurements under different conditions should elucidate this (e.g., an experimental procedure more similar to [37]), as would further study specifically to quantify the length and size of EPOC. We suggest that researchers might consider a 'scale' of taxa to compare the competing suitabilities of VeDBA and RocRM according to the types of motion exhibited by the animals, whereby animal movement changes from being mostly described by its dynamic component of acceleration towards predominantly the change in the static component.

Beyond energy expenditure estimations, the use of different timescales (i.e. differentials over varying timesteps) in analysis of animal movement rotations may be a valuable tool in inferring, and in turn describing, scales over which an animal moves (Fig. 2). Smaller time-steps in RocRM, for example over just a few seconds, can pick up the instantaneous changes that occur during a jump, where larger time-steps (for example, in this instance $60 \mathrm{~s}$ ) might best highlight longer-term changes in body posture (particularly if such body posture changes, relative to the plane of the sea bed, are a summation of slower, gradual, less dynamic movements such as drifts [28]). Indeed, different time scales of yaw-change have been shown to reveal fine-scale movement differences in Loggerhead turtles (Caretta caretta) that can be indicative of behaviour types better than DBA metrics alone [44]. Visualising these scales of movement, such as through density plots as shown here, may then show movement over different scales simultaneously to produce a 'fingerprint' for a species, individual or context and potentially be used as a means of comparing these against others. In Fig. 3, there is a clear bias towards scales of movement manifest at the largest time-step tested $\left(\operatorname{RocRM}_{60}\right.$, i.e. $60 \mathrm{~s}$ ). This is supported by the much larger Bayes factor upper bounds values and AIC evidence ratios for RocRM time-steps of 10 and $60 \mathrm{~s}$ compared to 1 or $5 \mathrm{~s}$. Additionally, the $p$ value prediction interval for RocRM $\mathrm{R}_{60}$ has bounds entirely below 0.05 , suggesting very high replicability and therefore that a time-step of $60 \mathrm{~s}$ does appear to be the most suitable for linking rotational movement to $\mathrm{O}_{2}$ consumption. We note, however, that increasing time intervals also allow the animal time to turn back on itself, affecting the angle traversed within the time interval and therefore the estimated angular costs. Researchers concerned about this miscalculation of the differentials might consider instead calculating the integral of each rotational axis over a given time-step; comparing the integral to the differentials may well identify instances of the animal turning back on itself.

A natural next step using $L$. truncata would be to derive estimates of energy expenditure through RocRM in free-living individuals to make ecologically relevant observations and inferences about this and related species. For example, 'energy landscapes' have typically been visualised and described for highly mobile species such as birds $[59,60]$ but, by using RocRM-derived estimates, spatial use and daily movement patterns could be framed more widely within the context of slow-moving benthic invertebrates. Additionally, RocRM may well convey much more information about an animal's movement type than VeDBA when movement data are matched to behavioural observations; here, there are clear differences in the observed peak profiles depending on the relative sizes of change in the pitch, roll and heading axes.

\section{Conclusions}

The particular viability of RocRM to predict oxygen consumption $\left(\mathrm{VO}_{2}\right)$ over different time intervals would indicate that it could work for a variety of differentially slow-moving species, even if their angular velocity is appreciably different from that of spider conchs. Further work should be conducted to understand the mechanisms behind the variability around the mean trend of RocRM vs $\mathrm{VO}_{2}$. Nonetheless, we have presented evidence suggesting that rotational movement metrics better correlate to energetic expenditure in slow-moving conchs than DBA. Using similar experiments to ours on species that will have fewer sources of movement not measured by attached tags would be an obvious first step to validating these results.

\section{Supplementary Information}

The online version contains supplementary material available at https://doi. org/10.1186/s40317-021-00255-x.

Additional file 1: Table S1. Criteria for model selection during stepwise removal of insignificant terms in linear mixed models. Models with and without the fixed-effect term 'mean temperature' were compared by ANOVA with maximum likelihood to produce the final models shown in Table 2.

\section{Acknowledgements}

We thank the Coastal \& Marine Resources Core Lab Services for their invaluable assistance in the setup and running of the experimental procedures. Thanks to Dr Hannah Williams for her assistance with statistical analysis. The Daily Diary tag housings were made by Phil Hopkins from Swansea University. We also thank Dr. Andrea Anton for assistance with the PME miniDOT loggers. We thank the three anonymous reviewers whose comments greatly improved this manuscript.

\section{Authors' contributions}

LWH and RPW conceived and designed the study with input from NRG, ECP and CMD. LWH and NRG conducted the static respirometry work and capture and release of specimens. LWH conducted data analysis with input from RPW, 
EPC and ML. MDH provided software support and implemented the RocRM metric within the DDMT software. All authors contributed to manuscript preparation. All authors read and approved the final manuscript.

\section{Funding}

This work was Funded by a KAUST-funded studentship from the Office for Sponsored Research, as part of the CAASE project and overarching Sensor Initiative.

\section{Availability of data and materials}

The dataset supporting the conclusions of this article is available in a Figshare repository, https://doi.org/10.6084/m9.figshare.9662609

\section{Declarations}

\section{Ethics approval and consent to participate}

All applicable international, national, and/or institutional guidelines for sampling, care and experimental use of animals were followed and all necessary approvals obtained. All procedures performed in studies involving animals were approved by the Swansea University Ethics Committee (SU-EthicsStudent-220119/1248). This article does not contain any studies with human participants.

\section{Consent for publication}

Not applicable.

\section{Competing interests}

The authors declare that they have no competing interests.

\section{Author details}

'Department of Biosciences, Singleton Campus, Swansea University, Wallace Building, Swansea SA2 8PP, UK. ${ }^{2}$ Red Sea Research Centre (RSRC) and Computational Biology Research Centre (CBRC), King Abdullah University of Science and Technology (KAUST), Thuwal, Saudi Arabia. ${ }^{3}$ Department of Computing Science, Swansea University, Swansea, UK.

Received: 23 January 2021 Accepted: 15 July 2021

Published online: 07 September 2021

\section{References}

1. Nagy KA, Girard IA, Brown TK. Energetics of free-ranging mammals, reptiles, and birds. Annu Rev Nutr. 1999;19:247-77.

2. Brown JH, Gillooly JF, Allen AP, Savage VM, West GB. Toward a metabolic theory of ecology. Ecology. 2004;85:1771-89.

3. Cooke SJ, Hinch SG, Wikelski M, Andrews RD, Kuchel LJ, Wolcott TG, et al. Biotelemetry: a mechanistic approach to ecology. Trends Ecol Evol. 2004;19:334-43.

4. Nathan R, Getz WM, Revilla E, Holyoak M, Kadmon R, Saltz D, et al. A movement ecology paradigm for unifying organismal movement research. Proc Natl Acad Sci. 2008;105:19052-9.

5. Anderson KJ, Jetz W. The broad-scale ecology of energy expenditure of endotherms. Ecol Lett. 2005;8:310-8.

6. Speakman JR. Body size, energy metabolism and lifespan. J Exp Biol. 2005;208:1717-30.

7. Halsey LG. Terrestrial movement energetics: current knowledge and its application to the optimising animal. J Exp Biol. 2016;219:1424-31.

8. Tomlinson S, Arnall SG, Munn A, Bradshaw SD, Maloney SK, Dixon KW, et al. Applications and implications of ecological energetics. Trends Ecol Evol. 2014;29:280-90.

9. Jeanniard-du-Dot T, Guinet C, Arnould JPY, Speakman JR, Trites AW. Accelerometers can measure total and activity-specific energy expenditures in free-ranging marine mammals only if linked to time-activity budgets. Funct Ecol. 2017;31:377-86.

10. Elliott KH. Measurement of flying and diving metabolic rate in wild animals: review and recommendations. Comp Biochem Physiol Part A Mol Integr Physiol. 2016;202:63-77.

11. Lifson N, McClintock R. Theory of use of the turnover rates of body water for measuring energy and material balance. J Theor Biol. 1966;12:46-74.
12. Speakman JR, Hambly C. Using doubly-labelled water to measure free-living energy expenditure: some old things to remember and some new things to consider. Comp Biochem Physiol Part A Mol Integr Physiol. 2016;202:3-9.

13. Gessaman JA. An evaluation of heart rate as an indirect measure of daily energy metabolism of the American kestrel. Comp Biochem Physiol Part A Physiol. 1980;65:273-89.

14. Green JA, Halsey LG, Wilson RP, Frappell PB. Estimating energy expenditure of animals using the accelerometry technique: activity, inactivity and comparison with the heart-rate technique. J Exp Biol. 2009;212:471-82.

15. Green JA. The heart rate method for estimating metabolic rate: review and recommendations. Comp Biochem Physiol Part A Mol Integr Physiol. 2011;158:287-304.

16. Butler PJ, Green JA, Boyd IL, Speakman JR. Measuring metabolic rate in the field: the pros and cons of the doubly labelled water and heart rate methods. Funct Ecol. 2004;18:168-83.

17. Gleiss AC, Wilson RP, Shepard ELC. Making overall dynamic body acceleration work: on the theory of acceleration as a proxy for energy expenditure. Methods Ecol Evol. 2011;2:23-33.

18. Halsey LG, Shepard ELC, Wilson RP. Assessing the development and application of the accelerometry technique for estimating energy expenditure. Comp Biochem Physiol Part A Mol Integr Physiol. 2011;158:305-14.

19. Shepard ELC, Wilson RP, Halsey LG, Quintana F, Laich AG, Gleiss AC, et al. Derivation of body motion via appropriate smoothing of acceleration data. Aquat Biol. 2008;4:235-41.

20. Wilson RP, White CR, Quintana F, Halsey LG, Liebsch N, Martin GR, et al. Moving towards acceleration for estimates of activity-specific metabolic rate in free-living animals: the case of the cormorant. J Anim Ecol. 2006;75:1081-90.

21. Qasem L, Cardew A, Wilson A, Griffiths I, Halsey LG, Shepard ELC, et al. Tri-axial dynamic acceleration as a proxy for animal energy expenditure; should we be summing values or calculating the vector? PLOS ONE. 2012; 7:e31187.

22. Payne NL, Gillanders BM, Seymour RS, Webber DM, Snelling EP, Semmens $J M$. Accelerometry estimates field metabolic rate in giant Australian cuttlefish Sepia apama during breeding. J Anim Ecol. 2011;80:422-30.

23. Robson AA, Halsey LG, Chauvaud L. Feet, heat and scallops: what is the cost of anthropogenic disturbance in bivalve aquaculture? R Soc Open Sci. 2016;3:150679.

24. Wright S, Metcalfe JD, Hetherington S, Wilson R. Estimating activityspecific energy expenditure in a teleost fish, using accelerometer loggers. Mar Ecol Prog Ser. 2014;496:19-32.

25. Lear KO, Whitney NM, Brewster LR, Morris JJ, Hueter RE, Gleiss AC. Correlations of metabolic rate and body acceleration in three species of coastal sharks under contrasting temperature regimes. J Exp Biol. 2017;220:397-407.

26. Halsey LG, Shepard ELC, Hulston CJ, Venables MC, White CR, Jeukendrup $A E$, et al. Acceleration versus heart rate for estimating energy expenditure and speed during locomotion in animals: tests with an easy model species, Homo sapiens. Zoology. 2008;111:231-41.

27. Wilson RP, Börger L, Holton MD, Scantlebury DM, Gómez-Laich A, Quintana $F$, et al. Estimates for energy expenditure in free-living animals using acceleration proxies: a reappraisal. J Anim Ecol. 2020;89:161-72.

28. Dujon AM, Stieglitz TC, Amice E, Webber DM. Snail leaps and bounds: drivers of the diel movement pattern of a large invertebrate, the Caribbean queen conch (Lobatus gigas), in a marginal inshore habitat. Can J Zool. 2019;97:436-45.

29. Zenone A, Ciancio JE, Badalamenti F, Buffa G, D'Anna G, Pipitone C, et al. Influence of light, food and predator presence on the activity pattern of the European spiny lobster Palinurus elephas: an investigation using tri-axial accelerometers. Ecol Indic. 2020;113:106174.

30. Lyons GN, Halsey LG, Pope EC, Eddington JD, Houghton JDR. Energy expenditure during activity in the American lobster Homarus americanus: correlations with body acceleration. Comp Biochem Physiol Part A Mol Integr Physiol. 2013;166:278-84.

31. Wilson RP, Griffiths IW, Legg PA, Friswell MI, Bidder OR, Halsey LG, et al. Turn costs change the value of animal search paths. Ecol Lett. 2013;16:1145-50. 
32. Duncan PF. Shellfish | commercially important molluscs. In: Cabellero B, editor. Encyclopaedia of food Sciences and nutrition. 2nd ed. Oxford: Academic Press; 2003. p. 5222-8.

33. Tewfik A, Guzman HM. Shallow-water distribution and population characteristics of Strombus gigas and S. costatus (Gastropoda: Strombidae) in Bocas del Toro, Panama. J Shellfish Res. 2003;22:789-94.

34. Leiva GE, Castilla JC. A review of the world marine gastropod fishery: evolution of catches, management and the Chilean experience. Rev Fish Biol Fish. 2002:11:283-300.

35. Berg CJ Jr. A comparative ethological study of Strombid gastropods. Behaviour. 1974;51:274-322.

36. Brownscombe JW, Wilson ADM, Samson E, Nowell L, Cooke SJ, Danylchuk AJ. Individual differences in activity and habitat selection of juvenile queen conch evaluated using acceleration biologgers. Endanger Species Res. 2015;27:181-8.

37. Lefevre S, Watson S-A, Munday PL, Nilsson GE. Will jumping snails prevail? Influence of near-future $\mathrm{CO}_{2}$, temperature and hypoxia on respiratory performance in the tropical conch Gibberulus gibberulus gibbosus. J Exp Biol. 2015;218:2991-3001.

38. Crossley SGM, Mackintosh KA, Wilson RP, Lester LJ, Griffiths IW, McNarry MA. Energy expenditure associated with walking speed and angle of turn in children. Eur J Appl Physiol. 2018;118:2563-76.

39. Rodgers GG, Tenzing P, Clark TD. Experimental methods in aquatic respirometry: the importance of mixing devices and accounting for background respiration. J Fish Biol. 2016;88:65-80.

40. Lighton JRB. Measuring metabolic rates: a manual for scientists. Oxford: Oxford University Press; 2008.

41. Lear KO, Gleiss AC, Whitney NM. Metabolic rates and the energetic cost of external tag attachment in juvenile blacktip sharks Carcharhinus limbatus. J Fish Biol. 2018;93:391-5.

42. Robson AA, Mansfield RP. Overinflated behavioural energetics: using dynamic body acceleration to accurately measure behaviour duration and estimate energy expenditure. Aquat Biol. 2014;21:121-6.

43. Williams HJ, Holton MD, Shepard ELC, Largey N, Norman B, Ryan PG, et al. Identification of animal movement patterns using tri-axial magnetometry. Mov Ecol. 2017. https://doi.org/10.1186/s40462-017-0097-x.

44. Gunner RM, Wilson RP, Holton MD, Scott R, Hopkins P, Duarte CM. A new direction for differentiating animal activity based on measuring angular velocity about the yaw axis. Ecol Evol. 2020;10:7872-86.

45. R Core Team. R: a language and environment for statistical computing Austria: R Foundation for Statistical Computing; 2019.

46. Bates D, Maechler M, Bolker B, Walker S. Fitting linear mixed-effects models using Ime4. J Stat Softw. 2015;67:1-48.

47. Crawley MJ. The R book. UK: Wiley; 2007.
48. Zuur AF, leno EN, Walker NJ, Saveliev AA, Smith GM. Mixed effects models and extensions in ecology with R. New York: Springer; 2009.

49. Nakagawa S, Schielzeth H. A general and simple method for obtaining $R^{2}$ from generalized linear mixed-effects models. Methods Ecol Evol. 2013:4:133-42.

50. Lazzeroni LC, Lu Y, Belitskaya-Lévy I. Solutions for quantifying P-value uncertainty and replication power. Nat Methods. 2016;13:107-8.

51. Halsey LG. The reign of the $p$-value is over: what alternative analyses could we employ to fill the power vacuum? Biol Lett. 2019. https://doi. org/10.1098/rsbl.2019.0174.

52. Benjamin DJ, Berger JO. Three Recommendations for Improving the Use of p-Values. Am Stat. 2019;73:186-91.

53. Randall JE. Contributions to the biology of the Queen Conch, Strombus gigas. Bull Mar Sci. 1964;14:246-95.

54. Secor SM. Specific dynamic action: a review of the postprandial metabolic response. J Comp Physiol B Biochem Syst Environ Physiol. 2009;179:1-56.

55. Robson AA, Chauvaud L, Wilson RP, Halsey LG. Small actions, big costs: the behavioural energetics of a commercially important invertebrate. J R Soc Interface. 2012:9:1486-98.

56. Halsey LG, Matthews PGD, Rezende EL, Chauvaud L, Robson AA. The interactions between temperature and activity levels in driving metabolic rate: theory, with empirical validation from contrasting ectotherms. Oecologia. 2015. https://doi.org/10.1007/s00442-014-3190-5.

57. Baker EJ, Gleeson TT. The effects of intensity on the energetics of brief locomotor activity. J Exp Biol. 1999;202:3081-7.

58. Baldwin J, England W. The properties and functions of alanopine dehydogenase and octopine dehydrogenase from the pedal retractor muscle of Strombidae (Class Gastropoda). Pac Sci. 1982;36:381.

59. Shepard ELC, Wilson RP, Rees WG, Grundy E, Lambertucci SA, Vosper SB. Energy landscapes shape animal movement ecology. Am Nat. 2013;182:298-312.

60. Wilson RP, Quintana F, Hobson VJ. Construction of energy landscapes can clarify the movement and distribution of foraging animals. Proc R Soc Biol. 2012;279:975-80

\section{Publisher's Note}

Springer Nature remains neutral with regard to jurisdictional claims in published maps and institutional affiliations.
Ready to submit your research? Choose BMC and benefit from:

- fast, convenient online submission

- thorough peer review by experienced researchers in your field

- rapid publication on acceptance

- support for research data, including large and complex data types

- gold Open Access which fosters wider collaboration and increased citations

- maximum visibility for your research: over $100 \mathrm{M}$ website views per year

At BMC, research is always in progress.

Learn more biomedcentral.com/submissions 